Original Article (short paper)

\title{
Elite coaches' opinion about the additional court player and the strategic-tactical structures in handball
}

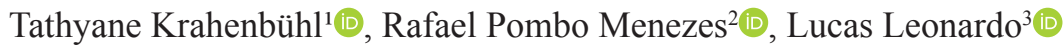 \\ ${ }^{1}$ Universidade Federal de Goiás, Faculdade de Educação Física e Dança, Goiânia, GO, Brasil; \\ ${ }^{2}$ Universidade de São Paulo, Escola de Educação Física e Esportes, Ribeirão Preto, SP, Brasil; \\ ${ }^{3}$ Universidade Estadual de Campinas, Faculdade de Educação Física, Campinas, SP, Brasil
}

\begin{abstract}
Aim: To investigate the speeches of elite handball coaches about the current strategic-tactical configuration after the rule change that allows the use of the seventh court player in the attack. Methods: Four elite handball coaches were interviewed (semi-structured) with specific questions about the main theme of this study. Coaches' speeches were analyzed using the Qualitative Content Analysis. Results: Three categories of analysis emerged from coaches' discourses: 1) a general overview of the current tactical application of the seventh court player: coaches report that there is no significant change in strategic-tactical structures previously established in handball; 2) main tactical strategies from the use of the rule change: the seventh court player used, mainly, like additional player in exclusion situations to maintain the numerical equality in the offensive phase, and to numerical superiority of the attack in the final minutes by the teams that are losing; and 3) main perspectives of change in the offensive, defensive and transitions systems, in which there is a concern with the restriction of the use of defensive system with open formation. Conclusion: there were no significant strategic changes in handball in attack or defense, and the use of the additional court player was used to maintain the numerical equality in the attack in situations of exclusion and, in some specific cases, aiming at numerical superiority in final and decisive moments of matches.
\end{abstract}

Keywords: team sports, sports coaching, handball, strategic-tactic structure.

\section{Introduction}

The evolutionary process of sport is a constant phenomenon which most of the transformations occurs from changes in the way of playing, influenced by the technical, tactical and strategic improvement or by the elaboration and insertion of new rules ${ }^{1,2}$.

In handball, an example of recent rule modification refers to the use of the additional court player. One strategic tactical action that was already being used was the participation of the goalkeeper as a court player, mainly in final situations of decisive matches to create the numerical superiority of the attack ${ }^{3,4}$.

However, an effective rule modification since the 2016 Olympic Games allows seven court players to be at the same time on the court, as long as the team is without a goalkeeper ${ }^{5}$. In other words, any court player may replace the goalkeeper during the offensive phase of own team, leaving their own goal empty.

The possibility of playing with seven court players may cause changes in tactical behavior of the teams in both attack and defense situations, especially if we consider that the spatial and temporal structures are directly related with the tactical behavior and the interaction of the players in the game context $t^{6,7}$.

The recent temporality of this change reflects in the current incipient scientific production on the use of the additional court player in handball, mostly through investigations that deepen in answers on the tactical understanding of the game with this new configuration and that bring statistical data from the use of match analysis.

Currently, research on this subject is still rare, and early work is still being published. An example is a study by Krahenbühl, Sousa, Leonardo, Galatti, Costa8, in which the number of goals scored, and the counterattacks suffered in symmetry and asymmetrical situations were verified in the two situations: using the additional player or not. This study verified that this strategy did not produce significant changes in men's handball games.

Thus, much of the knowledge about the tactical interactions used from this new strategic possibility of handball is still being elaborated and experienced by coaches who work with elite teams, based on their perceptions and own analyzes. Consequently, the access to the speeches of these coaches is an important source of knowledge considering the scenario presented above.

The option of collecting information from elite handball coaches is justified by their ability to analyze the efficiency of player and team performances, both of the team they lead and of the opposing teams, to elaborate some strategic possibilities for future games?.

Therefore, it is necessary to identify the possibilities of changes in the dynamics and in the strategic understanding of the handball game from this change of rules as well as it becomes necessary to discuss the possible reorganizations of 
the individual and group tactical actions, the offensive, and defensive systems, by coaches and players.

Identifying the elite coaches' speeches about a strategictactical phenomenon is essential to verify the current panorama of the modality, being important for the understanding of the strategies elaborated from the rule changes.

Therefore, this study aimed to investigate the current strategic-tactical organization in handball concerning the use of the additional court player based on the speeches of elite coaches.

\section{Methods}

\section{Study Design}

A qualitative research approach was adopted to search for elements from the experiences of the participants inserted in a sports context ${ }^{10}$ and is exploratory because it considers the perspectives and knowledge of the participants that relate to the question investigated ${ }^{11}$.

\section{Participants}

The criteria for the selection of the participants were the participation in the technical staff of the Brazilian women's handball team, in the last Olympic cycle (2013-2016) or the actual (2017-2020). The option to select coaches of women's handball teams was due to the ease of access to them and also to the relevance that the Brazilian women's handball in an international context.

Four coaches (three Brazilian and one Spanish) were interviewed (T1, T2, T3, and T4), from a universe of seven possible coaches, whose experience in international championships is about $13.2( \pm 7.2)$ years and the mean age is $45.25( \pm 10.68)$ years.

All participants are graduates of Physical Education or equivalent internationally. Only one coach does not have a postgraduate degree, and the others state that they have postgraduate degrees in sports (training, management or science applied to sports).

All the interviewees signed an Informed Consent Term, approved by the Research Ethics Committee of the local University under the number 85700518.1.0000.5083.

\section{Instruments}

Coaches were addressed during a training course of the Brazilian Handball Confederation and the Women's National Handball League. The interviews were scheduled in a free time provided by the coaches, in a private place and without noise (for a clean voice record).

The instruments used were: a questionnaire to characterize the participants and a semi-structured interview script, which consisted of the following questions: 1) "what is the main offensive tactical changes resulting from the use of the additional court player?"; and 2) "what are the main tactical defensive changes resulting from the use of the additional court player?". Throughout the interviews, we allowed new considerations related to the central problem of our study to emerge, addressing new questions in a particular way to each coach.

The interviews were recorded in full and we used the soft textual transcription, which is done word by word, but clearing the text non-conforming expressions, making it coherent and simple to understand ${ }^{12}$.

\section{Speeches analysis}

Speeches analysis was done by two researchers, both with more than 14 years of experience in handball (as a teacher or coach), one of them teaching higher education in a private institution and the other researcher is a professor at a Brazilian federal university and responsible for the discipline of handball in this institution. Both have researched on themes related to handball and sports pedagogy.

According to Mayring ${ }^{12}$ the interference of the researcher plain text is backed by their previous knowledge on the subject of research (supported by their personal impressions and the theoretical framework guiding the study). This aspect guarantees the possibility of condensing the information through processes of reduction and synthesis with the prevalence of the information in its quality and not the number of words present in the text, with the main care being the maintenance of the central ideas of the speeches.

After the transcription of the interviews, a Qualitative Content Analysis was used to analyze the speeches. First data reduction was performed each one, in which the materials were read and paraphrased. According to Mayring ${ }^{12}$, this is a form of reduction that allows the essential messages of the original text to be reproduced in a shorter text through generalization processes. Similar phrases are summarized in a single paraphrase that allows to substantially reduce the amount of information.

After this stage, the second data reduction was conducted, which, based on construction and integration, allowed the unification of the paraphrases of the respondents who were similar to each other in a single sentence that contained the same ideas, forming the answers-syntheses.

\section{Results and Discussion}

Based on the fact that this study deals with the investigation of the current strategic-tactical conjuncture in relation to the rule of use of the additional court player in handball, based on elite coaches' speeches, the analyzes revealed three main themes: 1) general overview of the actual use of the rule; 2) main strategies from the use of the rule; 3) main perspectives of change in offensive, defensive and transition phases.

Coaches interviewed showed that there was no consensus on the general conjecture that the new rule brought in tactical 
structures of handball, at national or international levels. It is possible to notice from the coaches' speeches that it is still very incipient the use of the seventh player (as well as the additional court player, in situations of numerical inferiority), possibly due to the novelty that this represents in the tactical conjuncture already well established.

The rule is still very recent and few teams are using the $7 x 6$, both in Brazil and in the world, and the male teams have used more than the female. (T1, T2, T4).

As it is something new the teams are still analyzing and studying how to use it, it needs time to know how its repercussion will be. (T2, T4).

In the coaches' opinion, it is possible to observe a tendency of the men's teams to risk more when using this new structure of attack. However, it is not yet well defined how the teams use that additional player, or what are the main strategies that will be adopted to use seven players in the attack.

Nonetheless, using an additional player in handball is nothing new. Before the International Handball Federation (IHF) ${ }^{5}$ changed the rule, some teams used the line-goalkeeper as attack resource, in which strategically a court player wore goalkeeper's uniform to get an offensive numerical superiority and, thus, to obtain advantages in the game in specific situations.

Garcia and Lorenzo ${ }^{4}$, in a review on the use of line-goalkeeper, identified that its use is, primarily, a strategy aiming at the numerical balance for the attacking team in cases of exclusions. In a study done with the matches of the European Handball Championship of 2016, Musa, Modolo, Tsuji, Barreira, Morato, Menezes $^{3}$ observed the same tendency of the use of the linegoalkeeper in cases of exclusions and identified that their use was predominant in the last 10 minutes of the game.

Research on match analysis shows that defending in numerical superiority has a decisive effect on the final results of handball matches ${ }^{13,14}$, besides that the positional game in numerical equality can be a determinant aspect for the definition of the winner or loser of the match ${ }^{6}$.

This contextualization on the line-goalkeeper and the rule change that currently allows seven players on the court to act in the attack, when replaced the goalkeeper, takes us to the next category of analysis of this study.

In the second theme, on how teams have been using the new rule, coaches have raised some more critical situations regarding the use of the additional court player. A unanimous finding of the new rule is that its use has been made, mainly, in situations of punishment, where the team suffers exclusion for 2 minutes and, to play in numerical equality in the attack, coaches use a court player in substitution to the goalkeeper.

It has been used mainly in situations of exclusion for 2 minutes, to maintain $6 x 6$ in the attack, which is bad, because when playing with the seventh player there is no more punishment in the attack situation, this punishment is only for half of the game, only for when it is in the defense. (T1, T2, T3, T4).
From this information, we noticed that the change in the rule did not influence the strategies used by the teams so far, and the strategy of using the line-goalkeeper was already common ${ }^{4}$ and only changed the dynamics of substitution. With the new rule, any player can leave the game for the return of the goalkeeper, minimizing the risk of withdrawing the goalkeeper momentarily from the match, as it may return more easily.

The advantage obtained by the team that was punished was widely criticized by the coaches interviewed, showing the dissatisfaction about the use of this strategy for this purpose. However, the teams already used this advantage in cases of exclusion using the line-goalkeeper ${ }^{3,15}$.

In addition to the advantage obtained by the team that has been punished with the exclusion, there are also other particular moments of the matches that are influenced by the use of the seventh player. Both T4 and T1 gave examples of final game situations when teams losing the game can benefit, or even be "harmed" by the new rule. Thus, according to T4, the use of the seventh court player can benefit from the numerical superiority: "I see the use in specific situations, such as when you are losing, in the final moments use the seventh player to enlarge the scoreboard (T4)".

The use of the seventh court player in the final minutes of the match is also not a recent strategy and therefore cannot be attributed to the new rule, but to the continuity of an earlier strategy in which the line-goalkeeper was used to create numerical superiority for the attack at that particular moment of the matches ${ }^{4}$. In this case, we assume that the rule was adapted to the previous strategies. However, according to T1, another strategy already consolidated for defense, such as using the individual defensive system to try to recover the ball quickly, can be hampered by the use of the seventh player:

\section{At the end of the game the teams that are losing, an alternative was to defend with the individual defensive system the whole court, and today if it does this has the seventh player and cannot do the individual defense. (T1)}

From these coaches' speeches, it is possible to observe that strategies for using the additional player of the court (or seventh player) are still restricted to specific situations of handball matches. Even so, coaches were questioned about the overall game structure, whether the use of $7 \times 6$ could change the current organization of tactical structures in both attack and defense. In this question, the coaches were cautious, saying they had doubts about whether this new rule would actually influence on already established tactical structures. In this sense, T2's response was the most emphatic about a future perspective on playing $7 \times 6$ :

I think it's going to be like the counterattack. Today it is difficult to imagine the slowest handball. I think the trend is to increase the use of $7 \times 6$, and will have the teams that will play well, but I do not think they will play the whole game, I think the benefits are more punctual, it is not a rule that will be used in all the situations (...). There are items 
to be considered for the use of the seventh player as the technical level, the category, the suit due to greater responsibility with the ball that the $7 x 6$ brings. I think handball will not be a constant $7 x 6$, this situation will be used in specific moments. (T2)

However, in addition to the particular situations as exclusions and in the final minutes of the matches, other strategies for the use of the additional player were suggested by the coaches. Although they say that more time is needed to figure out how to build tactical structures with seven players in the attack, coaches already identify some manifestations both in attack and defense when the game is in positional phase.

There is still no well-structured structure of how to use this seventh player in the attack, some teams do without an organized tactical action, with the use of a second pivot, one being more centralized and another more lateralized, at specific and punctual moments of the game, on the opposite side of the ball for rapid reversal to the sector where there is numerical superiority (T1, T2, T4).

The use of the second pivot, according to the coaches, seems to be one of the features most often used by the few teams that play with seven players in attack. However, coaches have made important considerations about how to play in numerical superiority.

The use is more punctual in situations, for example, that the team is having difficulty making a point. The game in numerical superiority is different from that in numerical equality. In superiority it is not necessary to be so fast, it is necessary to find the space empty and to look for the continuity to find the player more because one already has an advantage. In the game, equality there is the combat, tries to get the advantage by the movement of the ball, creating the superiority. Playing in $7 x 6$ loses this feature of the game (T1, T2, T3)

The coaches understand that there is a change in the internal logic of the handball game when one team has numerical superiority. In this way, the actions that consist of acquiring numerical and spatial advantage will change, because with numerical superiority in attack the logic is that the additional player is already unmarked.

In this sense, when in numerical equality, the teams strategically transform the offensive systems to induce errors in the defense and thus gain the advantage to be able to score ${ }^{16}$. In numerical superiority, the offensive players will need to have a speed of passes to find a free player to throw. Studies show that the attack positioned in numerical superiority has obtained a greater advantage in matches of handball, mainly against defensive systems structured in a line ${ }^{7}$.

If numerical superiority interferes with the logic of the offensive game, possibly the defensive strategy will also have changes. In numerical equality, there is a very wide variety of defensive systems that can be used in handball, such as closed or open defenses ${ }^{17}$, in one, two, three lines or individual defensive system ${ }^{18}$. Though, in particular, defenses in-depth that try to steal the ball through pressing the offensive players, the domain of a larger court space is worst when in numerically inferiority ${ }^{14,19}$.

When asked about the characteristics of defenses in a context where the seventh court player is most often used, coaches agree that their use will limit the use of more open defenses or have characteristics of dissuasion.

With the seventh player, the defense focusses on blocks, more retracted, at ball line. It will not be possible to defend as open, always have to have a player in 6 meters. It is a tendency to use 6:0, we will have to close the zone closer to the goal, reducing the possibilities of open and combined defenses, I have not yet seen a team playing against the seventh player using the 5:1 (T1, T2, T3, T4)

Only one of the coaches (T1), who told that it will be more difficult to maintain open defenses (like 3:3), stated that he does not believe that in the future handball will have a 6:0 system hegemony, stating that teams develop forms to defend on systems with at least one advanced player, as in the case of the $5: 1$ system.

I do not think it will have a system alone [6:0]. Some teams maintain the advanced defender in the $7 x 6$ to take the mobility of the ball, it is more exposed, but it takes the speed of the ball of the attack. (T1)

We observe that in handball, even before the inclusion of the additional court player rule, teams already tended to make defenses on a line, such as 6:0. Studies show that in high-level adult matches defensive systems like 6:0 and 5:1 are the most used $^{7,20}$, revealing the tendency of teams to use more closed defenses. A study that analyzed the frequency of the systems used by Brazil women's National Team in 2013 showed a predominance of the defensive system 6:0 throughout the matches or 5:0 when in numerical inferiority ${ }^{21}$.

However, the analysis of the use of the defensive system in lines does not provide an up-to-date view of these systems. The structure of defensive play closer to the goalkeeper's area, with passivity and little anticipation, seems to be uncommon in the current matches. Even using defenses that are considered closed, such as 6:0 or 5:1, players have behaved more actively to regain ball possession, to cause opponents' errors and to break the coordination of offensive actions, and these actions must be present in any defensive system, including in situations of numerical inferiority ${ }^{2,22}$.

Only one coach (T2) told about the defensive transition, who emphasize that teams wishing to play on $7 \times 6$ needs to practice the player's substitution with the goalkeeper as fast as possible. 
Despite the advantageous situation, you have to value continuity, such as the quick exchange of a player of court with the goalkeeper after losing possession of the ball, on the contrary, will have problems with the return (T2).

In this speech is perceived as a concern with one of the determining elements of a handball match: the counterattack. In a study with longitudinal analysis of international championships, it was observed that the teams with efficient counterattack are better classified in the international rankings ${ }^{23}$.

\section{Conclusions}

From this study, we can see that, in the coaches' conceptions, there have not yet been significant strategic changes in handball from the new rule of replacing the goalkeeper by a court player and the possibility of playing with seven players in the attack. In the current scenario, it remains the practice of using the additional player to maintain the numerical equality in the attack, specifically in situations of exclusion and, to reach numerical superiority in decisive moments of the matches.

In a future perspective, coaches do not consider it a possibility to have matches in which the situation of seven offensive players is prioritized all the time and possibly keep their use very close to the current structure.

From this perspective, this study is not limited to this moment, and it is necessary to expand researches on these possible changes for a longer time, in order to identify which influences will occur over the years.

\section{References}

1. Galatti LR, Scaglia AJ, Paes RR. Pedagogy of sport: contexts, evolution and perspectives.[Pedagogia do esporte: contextos, evolução e perspectivas]. Rev. bras. educ. fís. Esporte. 2006; 20(5): 171 .

2. Seco JDDR. The beginnings of the XXI century: evolution and tendencies of the game. E-Balonmano.com: Revista de Ciencias del deporte. 2006; 1(2):3-20.

3. Musa V, Modolo F, Tsuji G, Barreira C, Morato M, Menezes R. Participation of the line-goalkeeper in handball: analysis from match time, numeric relationship. Specific post, and match status. Rev. port. ciênc. Desporto. 2017; 17(S1.A):213-221.

4. Garcia A, Lorenzo J. About the use of "false goalkeeper" in attacking numerical inferiority: is this a new tactical-estrategical contribution? EBM.RECIDE. 2010; 6(1):3-27.

5. International Handball Federation (IHF). Rules of the game. Edition of 1 July 2016. Disponível em: http://ihf.info/files/ Uploads/NewsAttachments/0_New-Rules\%20of\%20the $\% 20$ Game_GB.pdf (Acessado em 14/11/2018).
6. Gutiérrez O, Fernández-Romero J, Borrás F. Use of the effectiveness of the game situations in inequality numerical in handball as predictive value of the final matches. EBM.RECIDE. 2010; 6(2):66-77.

7. Jarque DL, Foguet OC. Effectiveness of Offensive Systems in Handball. Apunts, Educ. fís. deport. 2012; 2(108):70-81.

8. Krahenbühl T, Sousa NPD, Leonardo L, Galatti LR, Costa GDCT. The use of the additional field player in handball: analysis of the Rio 2016 Olympic Games. RICYDE. Revista internacional de ciencias del deporte.2019; 57(15): 295-306.

9. Ohnjec K, Vuleta D, Milanović D, Gruić I. Performance indicators of teams at the 2003 World Handball Championship for women in Croatia. Kinesiology. 40(1):69-79.

10. Yin R. Qualitative Research from Start to Finish, Second Edition. New York: The Guilford Press, 2016.

11. Gil AC. How to design research projects. [Como elaborar projetos de pesquisa]. São Paulo: Atlas, 2002.

12. Mayring P. Qualitative content analysis: theoretical foundation, basic procedures and software solution. Klagenfurt, 2014.

13. Maféti E. Assessing defense strategies whilst in numerical superiority, European Handball Federation, Master Coach Theses from the Hungarian National Course: Master Coaches' Theses - Part 2, 2013.

14. Prieto J, Gómez MA, Sampaio J. Players' exclusions effects on elite handball teams' scoring performance during close games. Int J Perf Anal Spor. 2015;15(3):983-996.

15. Beiztegui-Casado C, Oliver-Coronado J, Sosa-González PI. Goalkeeper-field player in situation of offensive numerical inferiority in handball: penalty or advantage? Rev.int.med.cienc.act. fís.deporte, in press.

16. García JA, Legarra IA, Arellano JI, García T. Influence of the variables time and distance on the effectiveness of the game with transformations in four teams of high-level handball. Possibilities for the application in training. [Influencia de las variables tiempo y distancia en la eficacia del juego con transformaciones en cuatro equipos de balonmano de alto nivel. Posibilidades para la aplicación en el entrenamiento]. Eur. j. hum. mov. 2004; (12):71-86.

17. Menezes RP, dos Reis HHB. Defensive performance against different offensive systems in handball: analysis of technical-tactical scenario and reflections on teaching. Rev. bras. ciênc.esporte. 2017, 39(2): 168-175.

18. Krahenbühl T, Leonardo L. The teaching of individual defense in handball and its considerations for sports initiation. Pensar a Prática. 2018, 21(1):194-206.

19. Elena B. The importance of anticipation in increasing the defense efficiency in high performance handball. Procedia Soc Behav Sci. 2013, 76(1): 77-83.

20. Gutiérrez O, Férez JA. Quantification and assessment of the efficiency of defense systems used in a numerical equality based contextual frame in high level handball teams. Kronos. 2009; VII:113-116.

21. Silva VS, Albuquerque Rodrigues Filho E, Leão ICS, Viana MT, Tashiro T. Analysis of the defensive systems of the Brazilian women's handball adult selection. [Análise dos sistemas defensivos da seleção brasileira feminina adulta de handebol]. Rev Bras Esp Col. 2017, 1(1): 21-25. 
22. Ferreira Filho E, Sousa PRCD, Greco PJ. Evolution technician-tactics of handball (1986 at 1995) and the consequences to teaching-learning and training process. R. Min. Educ. Fís. 2001, 9(2):49-56.

23. Bilge M. Game Analysis of Olympic, World and European Championships in Men's Handball. J Hum Kinet. 2012, 35(1): 109-118.

\section{Corresponding author}

Tathyane Krahenbühl, Profa. Dra.

Faculdade de Educação Física e Dança,

Universidade Federal de Goiás

Avenida Esperança s/n, Campus Samambaia - CEP: 74.690-900, Goiânia, Goiás, Brasil

Email: tathy04n@gmail.com

Manuscript received on February 8, 2019

Manuscript accepted on June 12, 2019

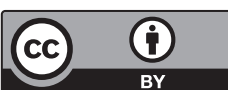

Motriz. The Journal of Physical Education. UNESP. Rio Claro, SP, Brazil - eISSN: 1980-6574-under a license Creative Commons - Version 4.0 